\title{
RNA Interference as a Prospective Tool for the Control of Human Viral Infections
}

\author{
Alesia Levanova* and Minna M. Poranen \\ Molecular and Integrative Biosciences Research Programme, Faculty of Biological and Environmental Sciences, University of \\ Helsinki, Helsinki, Finland
}

RNA interference (RNAi), which is mediated by small interfering RNAs (siRNAs) derived from viral genome or its replicative intermediates, is a natural antiviral defense in plants, fungi, and invertebrates. Whether RNAi naturally protects humans from viral invasion is still a matter of debate. Nevertheless, exogenous siRNAs are able to halt viral infection in mammals. The current review critically evaluates the production of antiviral siRNAs, delivery techniques to the infection sites, as well as provides an overview of antiviral siRNAs in clinical trials.

\section{OPEN ACCESS}

Edited by:

Akihide Ryo,

Yokohama City University, Japan

Reviewed by:

Shigeyoshi Harada,

National Institute of Infectious

Diseases (NIID), Japan

Takayuki Murata,

Fujita Health University, Japan

Norio Yamamoto,

Juntendo University, Japan

*Correspondence:

Alesia Levanova

alesia.levanova@helsinki.fi

Specialty section:

This article was submitted to

Virology,

a section of the journal

Frontiers in Microbiology

Received: 20 June 2018

Accepted: 22 August 2018

Published: 11 September 2018

Citation:

Levanova A and Poranen MM (2018) RNA Interference as a Prospective Tool for the Control of Human Viral

Infections. Front. Microbiol. 9:2151.

doi: 10.3389/fmicb.2018.02151
Keywords: RNA interference, antiviral siRNA, antiviral shRNA, siRNA production, siRNA delivery

\section{RNA INTERFERENCE AS ANTIVIRAL DEFENSE}

The term RNA interference (RNAi) is used to describe gene silencing at the mRNA level guided by small complementary non-coding RNA species. There are several classes of RNAi mediators, one of which, namely small interfering RNAs (siRNAs), facilitates antiviral immunity in plants, fungi, and invertebrates (Ding et al., 2004). The source of siRNAs during infection is viral double-stranded RNA (dsRNA), which is cleaved by cytoplasmic RNAse III family enzyme Dicer into 19-27 base pair (bp) long molecules with a perfectly complementary middle region and 2-nt overhangs on both $3^{\prime}$ ends. These siRNAs are incorporated into a multiprotein RNA-induced silencing complex (RISC). Following the strand separation, the antisense strand guides the RISC to recognize and cut target RNA transcripts (Fire et al., 1998; Elbashir et al., 2001; Macrae et al., 2006).

Whether RNAi is a functional antiviral pathway in mammals is still contentious (tenOever, 2017), since production of siRNA molecules from long dsRNAs cannot be explicitly demonstrated in mammalian cells due to the fact that dsRNA longer than 30 bp triggers activation of interferon (IFN) response (Minks et al., 1979; Elbashir et al., 2001) which shuts down the natural RNAi (Seo et al., 2013). However, mammalian cells do possess all the components of evolutionary conserved RNAi machinery (Shabalina and Koonin, 2008) that can be harnessed to inhibit the expression of cognate mRNA by exogenous siRNA molecules (Elbashir et al., 2001). The antiviral potential of siRNAs was first demonstrated against respiratory syncytial virus (RSV; Bitko and Barik, 2001) and thereafter numerous studies describing antiviral activity of siRNAs against viruses with DNA and RNA genomes in vitro and in vivo have been published (Gitlin et al., 2002; Jacque et al., 2002; Ge et al., 2003; Kapadia et al., 2003; Randall et al., 2003; Morrissey et al., 2005; Kumar et al., 2008; Geisbert et al., 2010; Paavilainen et al., 2017; Villegas et al., 2018). RNAi-based drugs appear to be a viable option to treat severe viral infections, against which effective vaccines or specific cure is not yet available, such as Ebola virus or emerging viruses. Furthermore, siRNAs are likely to become a valuable alternative to treat debilitating chronic infections caused by human immunodeficiency virus (HIV) and hepatitis B virus (HBV). Current care for chronic hepatitis 
$\mathrm{B}$ infection is a combination of nucleos(t)ide analogs and interferon (Su and Liu, 2017), while combination antiretroviral therapy, which targets viral enzymes as well as cellular entry receptors is used to treat HIV infection (Cihlar and Fordyce, 2016). However, these treatments are of limited effectiveness, toxic, impose the risk of developing drug resistance, and life-long since they only suppress the virus and do not lead to eradication of infection. Conversely RNAi-based drugs have a potential to achieve a functional cure and discontinue antiviral therapy.

\section{PRODUCTION OF RNA MOLECULES FOR RNAi}

\section{Selection of Target Sequences for RNAi}

The first step in production of antiviral siRNAs is in silico selection of highly conservative sequences in the targeted virus genome in order to achieve strong antiviral activity and avoid off-target effects. Specificity filters are used to exclude sequences with close similarity to mRNAs of human and model animal transcriptomes. Additionally, a number of sequence- and structure-based algorithms are applied to select the functionally most potent siRNA sequences (Reynolds et al., 2004; Tafer, 2014). However, this step is not needed when pools of siRNAs covering large regions of conserved sequences are used (see Enzymatic generation of siRNAs).

\section{Production of siRNAs}

Three approaches have been developed to generate antiviral siRNAs: (1) chemical synthesis; (2) enzymatic production; and (3) in vivo expression from siRNA expression cassette or vector.

\section{Chemical Synthesis of RNA Molecules}

Molecules of ssRNA are produced by automated solid-phase synthesis employing $2^{\prime}$-hydroxyl protecting groups that provide ribonucleoside phosphoramitides (Beaucage, 2008). Following the synthesis step, cognate ssRNAs are hybridized to form RNA duplexes. The accuracy of chemical RNA synthesis is often compromised, resulting in products of varying length and sequence. Therefore, each ssRNA must be tested by matrix-assisted laser desorption-ionization mass spectrometry, and produced siRNAs are analyzed by non-denaturing gel or capillary electrophoresis to confirm proper annealing of the strands ${ }^{1}$. Albeit the cost of synthesis per nucleotide has decreased dramatically over the past few years, chemical synthesis is still far from an economically sound approach. However, if the cost is not a limiting factor, this method is so far indispensable for applications that require large amounts of ultrapure siRNA molecules with defined sequence (e.g., clinical trials).

\section{Enzymatic Generation of siRNAs}

The main advantages of enzymatic production of siRNAs are low-cost and short preparation time. Therefore, this method can be applied for screening of the most potent siRNA sequences. Traditionally enzymatic production of siRNAs and

\footnotetext{
${ }^{1}$ https://www.thermofisher.com/us/en/home/references/ambion-tech-support/ rnai-sirna/tech-notes/five-ways- to-produce-sirnas.html.
}

longer dsRNAs has been based on in vitro transcription of DNA templates containing T7 polymerase promoter (Figure 1). T7 DNA-dependent RNA polymerase (DdRp) transcribes target DNA molecules in their sense and antisense orientation followed by the annealing step (Donzé and Picard, 2002; Sohail et al., 2003). The leader sequence added by T7 DdRp to the $5^{\prime}$ end of the synthesized ssRNA can be cleaved off by deoxyribozyme, while random nucleotides, that T7 DdRp might add to the $3^{\prime}$ end of ssRNA, do not have any considerable negative effect on siRNAs efficacy and safety (Sohail et al., 2003). The bacteriophage polymerases also incorporate $5^{\prime}$ triphosphates to their transcripts, which can induce a significant IFN response (Kim et al., 2004). However, treatment of synthesized ssRNA with alkaline phosphatase abrogates the IFN induction. The main disadvantage of T7 DdRp-based dsRNA production is a rather limited dsRNA yield because during hybridization step a significant amount of biologically inactive dsRNA is generated, especially in the case of long ssRNAs, due to formation of tertiary structures that prevent annealing of complementary sequences (Figure 1).

To avoid the drawbacks of inefficient annealing step, our laboratory has developed a single-tube dsRNA synthesis platform, where ssRNA generated by T7 DdRp is immediately used by bacteriophage Phi6 RNA-dependent RNA polymerase (RdRp) to synthesize a complementary RNA strand starting from the very $3^{\prime}$ end (Aalto et al., 2007; Figure 1). Phi6 RdRp is a highly processive enzyme lacking template specificity and providing an opportunity to produce dsRNA molecule of virtually any length from any heterologous template (Makeyev and Bamford, 2000). Besides T7 DdRp and Phi6 RdRp, other viral polymerases such as DdRp from bacteriophages T3, SP6, cyanophage Syn5 (Zhu et al., 2015), and noroviral RdRp (Rohayem et al., 2006) can be used for RNA synthesis in vitro. The generated dsRNA molecules can be subsequently digested with either bacterial RNase III (Yang et al., 2002), recombinant eukaryotic Dicer (Gimenez-Barcons et al., 2007; Romanovskaya et al., 2012), or RNase T1 (Hannus et al., 2014) to get a pool of target-specific siRNA molecules.

Enzymatic approach for siRNAs production allows to generate siRNA pool against any virus in a relatively short time, which is essential in case of a sudden virus outbreak. A robust and fairly fast protocol for the purification of enzymatically-produced siRNAs has been developed in our laboratory, where siRNAs obtained by Giardia Dicer digestion are purified by anionexchange chromatography on monolithic QA column followed by desalting on Sephadex G25 column (Romanovskaya et al., 2013). The siRNAs obtained are of high purity and safe for animals (Paavilainen et al., 2017).

A diverse siRNA pool derived from a long fragment of viral genome, which mimics the natural RNAi-based antiviral defense, is more protective than a single-site siRNA. Even RNA viruses with high mutation potential can be effectively inhibited with a mixture of siRNAs and escape mutants are not generated that easily compared to a single siRNA (Gitlin et al., 2005). Importantly, each siRNA species in a pool is present at very low concentration diluting off-target effects below detection limit. A number of studies demonstrated that siRNA pools generated enzymatically are highly effective in silencing of the target genes without causing obvious off-target effects (Aalto 


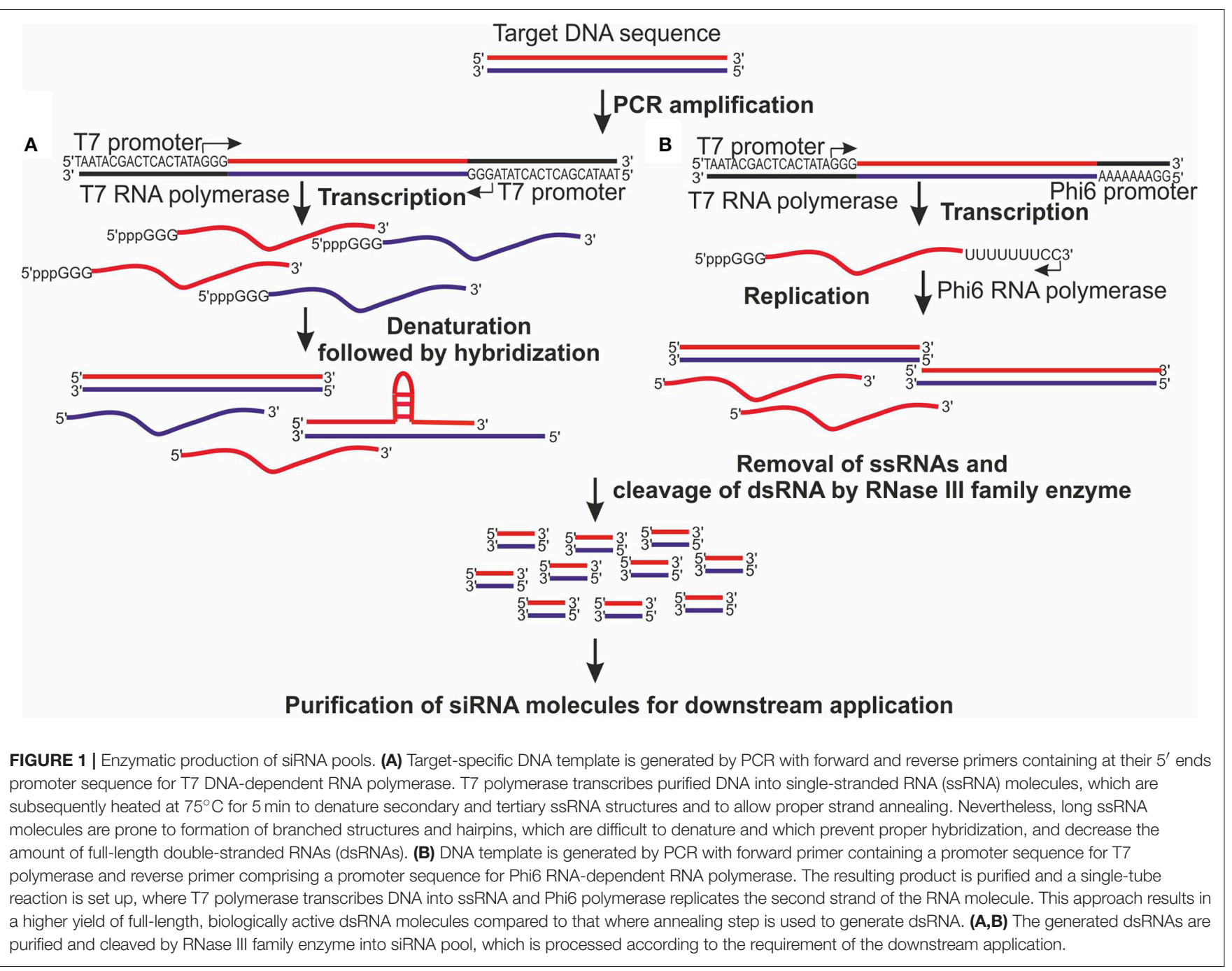

et al., 2007; Nygårdas et al., 2009; Romanovskaya et al., 2012; Hannus et al., 2014; Paavilainen et al., 2016, 2017). Nevertheless, despite numerous benefits of using siRNA pools, there are no enzymatically-produced siRNA mixtures in clinical trials.

A possibility to generate dsRNA in mammalian or bacterial cells, using viral RNA polymerases, has been demonstrated, which potentially allows to scale-up the production at low cost (Aalto et al., 2007; Heninger and Buchholz, 2007; Huang and Lieberman, 2013; Enayati et al., 2016). However, these systems still need further elaboration and most probably will not have clinical applications but, for instance, can be used in agriculture (Tenllado et al., 2003; Niehl et al., 2018).

\section{In vivo Expression From siRNA Expression Vector}

Molecules of siRNAs can also be produced by Dicer cleavage of small hairpin RNA (shRNA) transcribed in a cell from an expression cassette containing a polymerase III promoter (U6 or H1), a DNA template of desired shRNA sequence, and transcription stop signal (Brummelkamp et al., 2002). The expression cassette can be integrated into a plasmid or viral vector and thus delivered into cells. The main advantage of siRNA expression vectors is that they are suitable for long-term applications.

\section{DELIVERY OF SiRNAS FOR CLINICAL APPLICATIONS}

Depending on the target tissue, siRNA therapeutics can be administered either locally or systemically via intravenous injection. However, unprotected siRNAs are prone to rapid degradation by ubiquitous endo- and exonucleases and they are undetectable in the blood already $10 \mathrm{~min}$ after administration (DeVincenzo et al., 2008). Due to a strong anionic charge of the phosphate backbone, siRNAs cannot passively diffuse through negatively charged cellular membranes. Moreover, siRNA molecules can be sensed by the cellular receptors and induce IFN response or other off-target effects (Anderson et al., 2008; Sioud, 2009; Olejniczak et al., 2011). Several approaches have been developed to enhance siRNA stability and promote its cellular uptake. The most widely used approach 
involves introduction of chemical modifications to ribose sugar, phosphate linkage, or base of nucleotide (Kaczmarek et al., 2017). RNA can be easily modified during chemical synthesis. Furthermore, bacteriophage polymerases (e.g., DdRps from T7 and Syn5) are also able to utilize modified NTPs for RNA synthesis (Zhu et al., 2015; Sun and Riggs, 2017). Modifications of the sugar backbone at the $2^{\prime}$-position of the ribose ring $\left[2^{\prime}-\mathrm{O}\right.$ methyl ( $2^{\prime}$-OMe), $2^{\prime}$-deoxy, and $2^{\prime}$-fluor] not only have no impact on gene silencing indicating that $2^{\prime}-\mathrm{OH}$ group is dispensable for functional RNAi pathway, but demonstrate increased siRNA plasma stability and consequently enhanced in vivo efficacy with reduced off-target effects (Chiu and Rana, 2003). Moreover, these modification render siRNAs unrecognizable for immune system (Morrissey et al., 2005).

RNA delivery to the target cells can be achieved by viral and non-viral vectors. For the delivery to animals and humans, adeno-associated virus (AAV) vector is the first choice since it has been proved to be non-toxic, non-pathogenic, easy to produce, and it does not integrate into human genome (Naso et al., 2017). Of the non-viral vectors, nanoparticles comprised of cationic polymers (poly-L-lysine, polyamidoamine, polyethyleneimine, chitosan) or lipids are the best studied delivery vehicles (Kaczmarek et al., 2017). In addition to nanoparticles, direct conjugates of bioactive ligands to siRNA molecules can facilitate their entry to the cell. Once siRNA is complexed with positively charged polymer or lipid molecules, it can approach cell membrane close enough to be internalized via micropinocytosis or clathrin-dependent pathway (Pozzi et al., 2014). If siRNA is conjugated with specific ligands (e.g., antibodies) that recognize receptor molecules on a particular cell type, it can be taken up by receptor-mediated endocytosis. In this case endosome escape agents must be applied to facilitate siRNA transport to cytosol, where it can be used by RNAi machinery (Dominska and Dykxhoorn, 2010).

Topical delivery of antiviral siRNA seems to be a viable approach for mucosal surfaces and has been used to inhibit herpes simplex virus (HSV) and RSV in animal models (Bitko et al., 2005; Palliser et al., 2006; Alvarez et al., 2009; Paavilainen et al., 2017). In clinical studies, human respiratory tract can be easily achieved by inhalation of an aerosol indicating a plausible administration route for antivirals against respiratory viruses. For a detailed review on the approaches to siRNA delivery please refer to (Musacchio and Torchilin, 2013; Kaczmarek et al., 2017).

\section{ANTIVIRAL RNAi-BASED THERAPEUTICS}

The first siRNA with documented effect in humans was ALNRSV01, a 19 bp RNA duplex with two (2'-deoxy) thymidine overhangs on both $3^{\prime}$ ends to prevent its nuclease degradation (Elbashir et al., 2001; Alvarez et al., 2009). ALN-RSV01 targets a highly conserved region in the mRNA of RSV nucleocapsid protein. The activity of naked ALN-RSV01 siRNAs has been tested in adults experimentally infected with wild-type RSV. The siRNA was applied daily in the form of nasal spray, 2 days before and 3 days after RSV infection. Intranasal ALN-RSV01 administration was safe and well tolerated and resulted in a $38 \%$ decrease in the number of infected people (DeVincenzo et al., 2010). Furthermore, ALN-RSV01 has been shown to reduce the risk of bronchiolitis obliterans syndrome in RSV-infected lung transplant patients in Phase 2 randomized, double-blind, placebo-controlled trials (Zamora et al., 2011; Gottlieb et al., 2016). Alnylam Pharmaceuticals had been developing a nasally administered formulation of asvasiran sodium (ALN-RSV01). However, in 2014 clinical trials were suspended for undisclosed reason. In our opinion, this could be related to the emergence of drug resistant viruses, which are easily generated if only a single-site siRNA molecule is used.

At least eight anti-HBV siRNA formulations have been in clinical trials (Table 1; Flisiak et al., 2018). Nevertheless the results from these trials are mostly reported at different scientific meetings instead of publications in peer-reviewed journals and, therefore, the detailed information is scarce. In this paragraph we will focus on siRNAs developed by Arrowhead Pharmaceuticals due to the abundance of the published data available for analysis. The first generation anti-HBV siRNA pool, ARC-520, was comprised of two synthetic siRNAs targeting the common region at the $3^{\prime}$ end of all $\mathrm{HBV}$ transcripts from episomal HBV DNA. The siRNAs were conjugated to cholesterol, which facilitates the cellular uptake and protects from degradation by serum RNAses (Schroeder et al., 2010). These conjugates were intravenously co-injected with polymerbased system (Rozema et al., 2007), which was composed of amphipathic membrane active peptide, required for endosome escape, and $\mathrm{N}$-acetylgalactoseamine, responsible for hepatocytespecific delivery via asialoglycoprotein receptor that is highly expressed on the surface of hepatocytes (Wooddell et al., 2013; Nair et al., 2014). ARC-520 tolerability and pharmacokinetics has been studied in healthy volunteers with no indicated adverse effects (Schluep et al., 2017). However, the data from a phase II clinical trials (Wooddell et al., 2017) have shown that a number of patients had only minimal response to ARC-520 treatment due to the integration of the HBV genome into the host DNA, which led to the loss of the target sites for ARC-520 (Wooddell et al., 2017). Therefore, the next formulation, ARC521 , in addition to already validated siRNA sequences included siRNA targeting viral mRNA expressed from the integrated HBV genome. Although siRNAs themselves were well tolerated in humans, endosome escape agent caused some toxicity in experimental animals. Therefore, Arrowhead Pharmaceuticals has switched to the development of the second generation siRNAbased drug ARO-HBV, in which the formulation of excipient has been changed. The preclinical studies have shown that APO-HBV has significant antiviral activity, and its doses up to $300 \mathrm{mg} / \mathrm{kg}$ given weekly are well tolerated in laboratory animals (Wooddell et al., 2018) ${ }^{2}$.

In spite of tremendous efforts put into the development of treatment of infection with HIV, currently only one patient has attained functional recovery, and no HIV can be detected in his

\footnotetext{
${ }^{2}$ http://ir.arrowheadpharma.com/static-files/9de6c80f-459a-419a-87a0-
} f82125d0196b. 


\begin{tabular}{|c|c|c|c|c|c|c|c|c|c|}
\hline 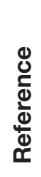 & 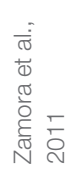 & 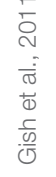 & 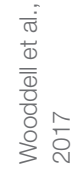 & $\mathbb{z}$ & 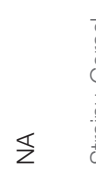 & 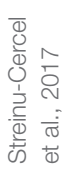 & $\mathbb{z}$ & 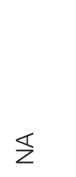 & $\Sigma$ \\
\hline 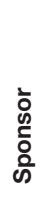 & 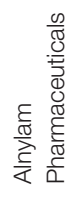 & 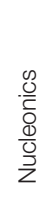 & 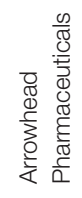 & 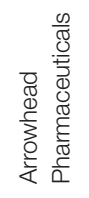 & 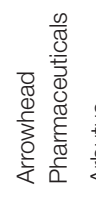 & 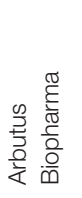 & 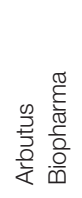 & 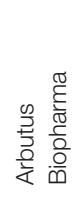 & 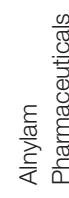 \\
\hline 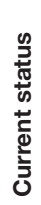 & 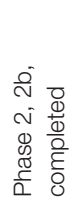 & $\begin{array}{l}\bar{\Phi} \\
\overline{\mathbb{O}} \\
\frac{\pi}{\alpha} \\
\overline{0}\end{array}$ & 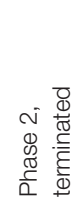 & 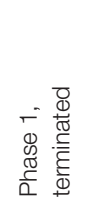 & 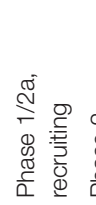 & 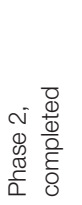 & $\begin{array}{l}\bar{\Phi} \\
\Phi \\
\bar{\Xi} \\
\bar{\alpha}\end{array}$ & 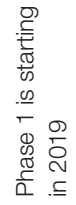 & \\
\hline
\end{tabular}
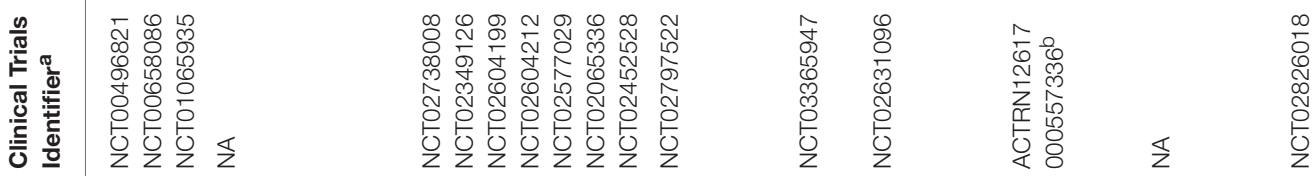

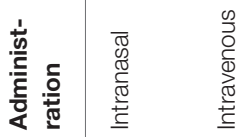
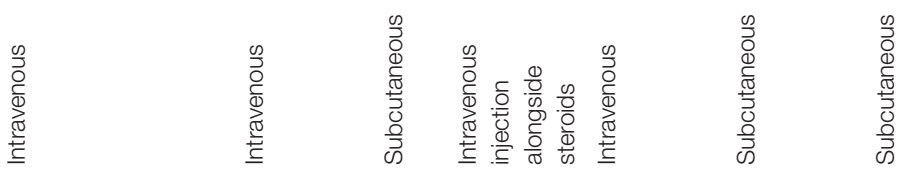

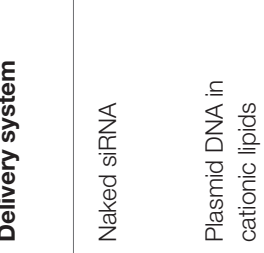
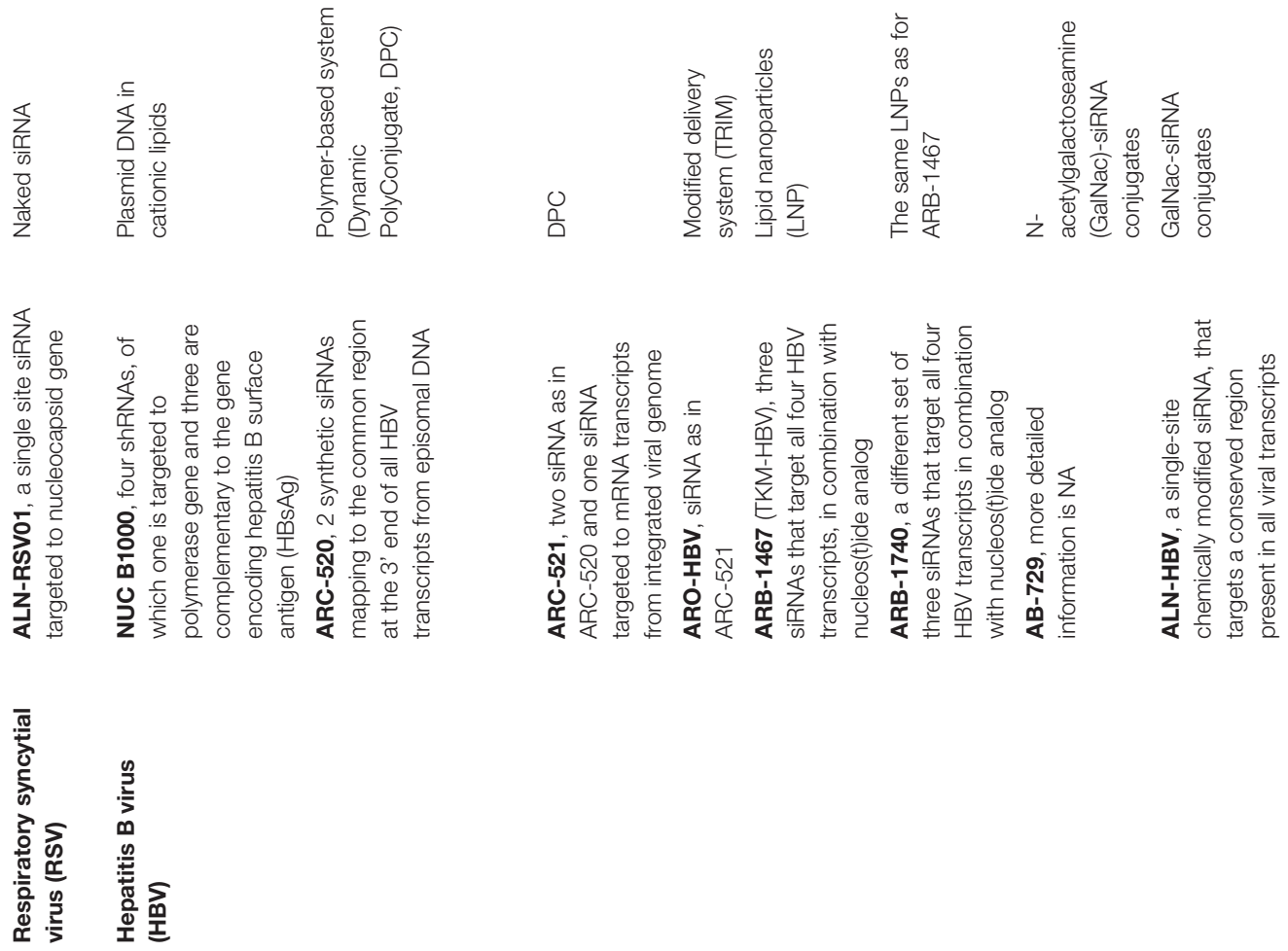


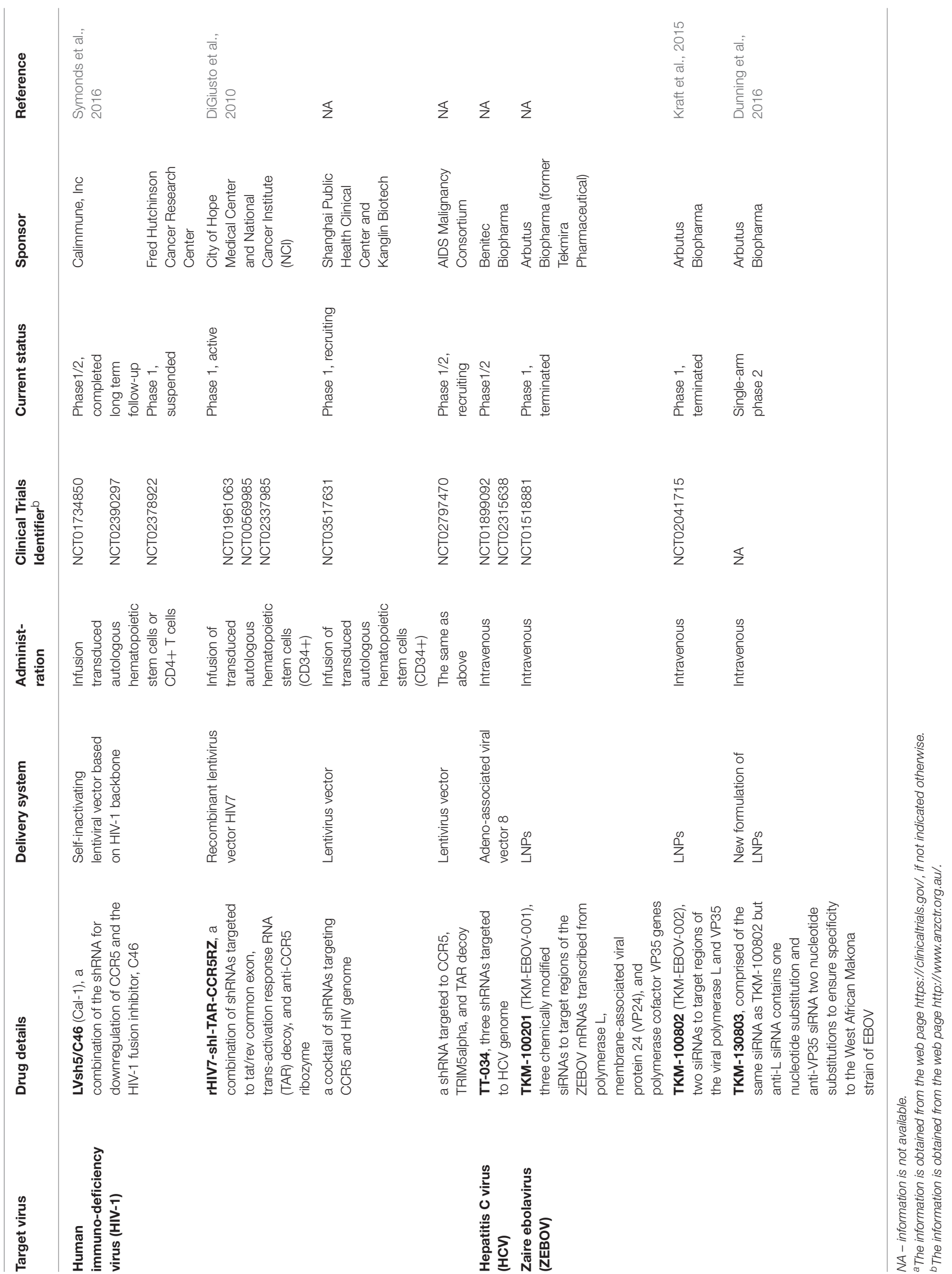


blood or other tissues tested (Hütter et al., 2009). This HIVinfected person developed an acute myeloid leukemia and was subjected to hematopoietic stem cell transplantation in 2007. Notably, a donor had a 32 bp deletion in both alleles coding for chemokine receptor CCR5 (Hütter et al., 2009), and the majority of HIV-1 viruses utilize CCR5 as a co-receptor to enter CD4+ cells (Alkhatib, 2009). A number of phase I/II clinical studies (Table 1) try to mimic the conditions under which the functional recovery was achieved and transduce autologous hematopoietic CD34+ stem cells with lentiviral vectors carrying multiplexed shRNA which target not only conserved regions in HIV genome, but also the host CCR5 gene. For a detailed review of RNAi-based therapies against HIV refer to (Bobbin et al., 2015; Scarborough and Gatignol, 2017).

A pool of three chemically modified siRNAs preventing synthesis of Zaire ebolavirus (ZEBOV) polymerase, viral proteins 24, and 35 completely protected rhesus macaques from lethal infection (Geisbert et al., 2010). This siRNA formulation with some modifications (Table 1), lately referred to as TKM-Ebola, was subsequently applied to treat humans during the ZEBOV outbreak in West Africa in 2013-2016. However, TKM-Ebola did not improve survival, which might be connected to a poor design of the clinical trials and inclusion of only terminally sick patients with high viral loads (Cross et al., 2018).

Two clinical trials have been initiated to assess the efficacy and safety of shRNA-based TT-034 therapeutics, which was created for chronic hepatitis $\mathrm{C}$ treatment and delivered to hepatocytes by AAV vector. TT-034 was shown to be safe and welltolerated. However, in February 2016 Benitec Biopharma decided

\section{REFERENCES}

Aalto, A. P., Sarin, L. P., van Dijk, A. A., Saarma, M., Poranen, M. M., Arumäe U., et al. (2007). Large-scale production of dsRNA and siRNA pools for RNA interference utilizing bacteriophage phi6 RNA-dependent RNA polymerase. RNA 13, 422-429. doi: 10.1261/rna.348307

Alkhatib, G. (2009). The biology of CCR5 and CXCR4. Curr. Opin. HIV AIDS 4, 96-103. doi: 10.1097/COH.0b013e328324bbec

Alvarez, R., Elbashir, S., Borland, T., Toudjarska, I., Hadwiger, P., John, M., et al. (2009). RNA interference-mediated silencing of the respiratory syncytial virus nucleocapsid defines a potent antiviral strategy. Antimicrob. Agents Chemother. 53, 3952-3962. doi: 10.1128/aac.00014-09

Anderson, E., Boese, Q., Khvorova, A., and Karpilow, J. (2008). Identifying siRNAinduced off-targets by microarray analysis. Methods Mol. Biol. 442, 45-63. doi: 10.1007/978-1-59745-191-8_4

Beaucage, S. L. (2008). Solid-phase synthesis of siRNA oligonucleotides. Curr. Opin. Drug Discov. Devel. 11, 203-216.

Bitko, V., and Barik, S. (2001). Phenotypic silencing of cytoplasmic genes using sequence-specific double-stranded short interfering RNA and its application in the reverse genetics of wild type negative-strand RNA viruses. BMC Microbiol. $1: 34$

Bitko, V., Musiyenko, A., Shulyayeva, O., and Barik, S. (2005). Inhibition of respiratory viruses by nasally administered siRNA. Nat. Med. 11, 50-55. doi: $10.1038 / \mathrm{nm} 1164$

Bobbin, M. L., Burnett, J. C., and Rossi, J. J. (2015). RNA interference approaches for treatment of HIV-1 infection. Genome Med. 7:50. doi: 10.1186/s13073-015-0174-y

Brummelkamp, T. R., Bernards, R., and Agami, R. (2002). A system for stable expression of short interfering RNAs in to discontinue hepatitis $\mathrm{C}$ program due to low commercial opportunities ${ }^{3}$.

In conclusion, the development of RNAi-based therapeutics is still in its early stage and has experienced numerous pitfalls. Nonetheless, it has already been demonstrated that siRNAs can effectively inhibit the replication of various viruses despite different mechanisms they evolved to resist the pressure imposed by immune system and antiviral drugs. However, the possibility of generation of escape mutants, recently discovered inhibitors of RNAi in human viruses (Fabozzi et al., 2011; Qiu et al., 2017), and complex interactions between RNAi and interferon pathways (Kok et al., 2011; Seo et al., 2013; Maillard et al., 2016) must be taken into consideration when designing new antiviral siRNA molecules. Furthermore, there are still unresolved issues with safe and efficient delivery of siRNAs to the target tissues and cells, which can be unraveled by fundamental research in the area.

\section{AUTHOR CONTRIBUTIONS}

$\mathrm{AL}$ and MMP conceptualization, $\mathrm{AL}$ manuscript draft, $\mathrm{AL}$ and MMP manuscript revision.

\section{FUNDING}

The work done in the laboratory has been supported by Finnish cultural foundation (AL), Jane and Aatos Erkko Foundation (MMP), and Sigrid Juselius foundation (MMP).

${ }^{3}$ https://www.prnewswire.com/news-releases/update-on-tt-034-hepatitis-cclinical-trial-300226692.html. mammalian cells. Science 296, 550-553. doi: 10.1126/science.10 68999

Chiu, Y. L., and Rana, T. M. (2003). siRNA function in RNAi: a chemical modification analysis. RNA 9, 1034-1048. doi: 10.1261/rna.5103703

Cihlar, T., and Fordyce, M. (2016). Current status and prospects of HIV treatment. Curr. Opin. Virol. 18, 50-56. doi: 10.1016/j.coviro.2016.03.004

Cross, R. W., Mire, C. E., Feldmann, H., and Geisbert, T. W. (2018). Post-exposure treatments for Ebola and Marburg virus infections. Nat. Rev. Drug Discov. 17, 413-434. doi: 10.1038/nrd.2017.251

DeVincenzo, J., Cehelsky, J. E., Alvarez, R., Elbashir, S., Harborth, J., Toudjarska, I., et al. (2008). Evaluation of the safety, tolerability and pharmacokinetics of ALNRSV01, a novel RNAi antiviral therapeutic directed against respiratory syncytial virus (RSV). Antiviral Res. 77, 225-231. doi: 10.1016/j.antiviral.2007.11.009

DeVincenzo, J., Lambkin-Williams, R., Wilkinson, T., Cehelsky, J., Nochur, S., Walsh, E., et al. (2010). A randomized, double-blind, placebo-controlled study of an RNAi-based therapy directed against respiratory syncytial virus. Proc. Natl. Acad. Sci. U.S.A. 107, 8800-8805. doi: 10.1073/pnas.0912186107

DiGiusto, D. L., Krishnan, A., Li, L., Li, H., Li, S., Rao, A., et al. (2010). RNAbased gene therapy for HIV with lentiviral vector-modified CD34 $(+)$ cells in patients undergoing transplantation for AIDS-related lymphoma. Sci. Transl. Med. 2:36ra43. doi: 10.1126/scitranslmed.3000931

Ding, S. W., Li, H., Lu, R., Li, F., and Li, W. X. (2004). RNA silencing: a conserved antiviral immunity of plants and animals. Virus Res. 102, 109-115. doi: 10.1016/j.virusres.2004.01.021

Dominska, M., and Dykxhoorn, D. M. (2010). Breaking down the barriers: siRNA delivery and endosome escape. J. Cell Sci. 123(Pt 8), 1183-1189. doi: $10.1242 /$ jcs.066399

Donzé, O., and Picard, D. (2002). RNA interference in mammalian cells using siRNAs synthesized with T7 RNA polymerase. Nucleic Acids Res. 30:e46. 
Dunning, J., Sahr, F., Rojek, A., Gannon, F., Carson, G., Idriss, B., et al. (2016). Experimental Treatment of Ebola Virus Disease with TKM130803: A Single-Arm Phase 2 Clinical Trial. PLoS Med. 13:e1001997. doi: 10.1371/journal.pmed.1001997

Elbashir, S. M., Harborth, J., Lendeckel, W., Yalcin, A., Weber, K., and Tuschl, T. (2001). Duplexes of 21-nucleotide RNAs mediate RNA interference in cultured mammalian cells. Nature 411, 494-498. doi: 10.1038/35078107

Enayati, S., Azizi, M., Aminollahi, E., Ranjvar Shahrivar, M., and Khalaj, V. (2016). T7-RNA polymerase dependent RNAi system in Aspergillus fumigatus: a proof of concept study. FEMS Microbiol. Lett. 363:fnw029. doi: 10.1093/femsle/fnw029

Fabozzi, G., Nabel, C. S., Dolan, M. A., and Sullivan, N. J. (2011). Ebolavirus proteins suppress the effects of small interfering RNA by direct interaction with the mammalian RNA interference pathway. J. Virol. 85, 2512-2523. doi: 10.1128/jvi.01160-10

Fire, A., Xu, S., Montgomery, M. K., Kostas, S. A., Driver, S. E., and Mello, C. C. (1998). Potent and specific genetic interference by double-stranded RNA in Caenorhabditis elegans. Nature 391, 806-811. doi: 10.1038/35888

Flisiak, R., Jaroszewicz, J., and Łucejko, M. (2018). siRNA drug development against hepatitis B virus infection. Expert Opin. Biol. Ther. 18, 609-617. doi: 10.1080/14712598.2018.1472231

Ge, Q., McManus, M. T., Nguyen, T., Shen, C. H., Sharp, P. A., Eisen, H. N., et al. (2003). RNA interference of influenza virus production by directly targeting mRNA for degradation and indirectly inhibiting all viral RNA transcription. Proc. Natl. Acad. Sci. U.S.A. 100, 2718-2723. doi: 10.1073/pnas.0437841100

Geisbert, T. W., Lee, A. C., Robbins, M., Geisbert, J. B., Honko, A. N., Sood, V., et al. (2010). Postexposure protection of non-human primates against a lethal Ebola virus challenge with RNA interference: a proof-of-concept study. Lancet 375, 1896-1905. doi: 10.1016/s0140-6736(10)60357-1

Gimenez-Barcons, M., Clotet, B., and Martinez, M. A. (2007). Endoribonucleaseprepared short interfering RNAs induce effective and specific inhibition of human immunodeficiency virus type 1 replication. J. Virol. 81, 10680-10686. doi: $10.1128 /$ jvi.00950-07

Gish, R. G., Satishchandran, C., Young, M., and Pachuk, C. (2011). RNA interference and its potential applications to chronic HBV treatment: results of a Phase I safety and tolerability study. Antivir. Ther. 16, 547-554. doi: $10.3851 / \mathrm{imp} 1798$

Gitlin, L., Karelsky, S., and Andino, R. (2002). Short interfering RNA confers intracellular antiviral immunity in human cells. Nature 418, 430-434. doi: 10.1038 /nature00873

Gitlin, L., Stone, J. K., and Andino, R. (2005). Poliovirus escape from RNA interference: short interfering RNA-target recognition and implications for therapeutic approaches. J. Virol. 79, 1027-1035. doi: 10.1128/jvi.79.2.1027-1035.2005

Gottlieb, J., Zamora, M. R., Hodges, T., Musk, A. W., Sommerwerk, U., Dilling, D., et al. (2016). ALN-RSV01 for prevention of bronchiolitis obliterans syndrome after respiratory syncytial virus infection in lung transplant recipients. J. Heart Lung Transplant. 35, 213-221. doi: 10.1016/j.healun.2015.08.012

Hannus, M., Beitzinger, M., Engelmann, J. C., Weickert, M. T., Spang, R., Hannus, S., et al. (2014). siPools: highly complex but accurately defined siRNA pools eliminate off-target effects. Nucleic Acids Res. 42, 8049-8061. doi: 10.1093/nar/gku480

Heninger, A. K., and Buchholz, F. (2007). Production of endoribonucleaseprepared short interfering RNAs (esiRNAs) for specific and effective gene silencing in mammalian cells. CSH Protoc. 2007:pdb.prot4824. doi: $10.1101 / p d b . p r o t 4824$

Huang, L., and Lieberman, J. (2013). Production of highly potent recombinant siRNAs in Escherichia coli. Nat. Protoc. 8, 2325-2336. doi: $10.1038 /$ nprot.2013.149

Hütter, G., Nowak, D., Mossner, M., Ganepola, S., Müssig, A., Allers, K., et al. (2009). Long-term control of HIV by CCR5 Delta32/Delta32 stem-cell transplantation. N. Engl. J. Med. 360, 692-698. doi: 10.1056/NEJMoa0802905

Jacque, J. M., Triques, K., and Stevenson, M. (2002). Modulation of HIV-1 replication by RNA interference. Nature 418, 435-438. doi: 10.1038/nature00896

Kaczmarek, J. C., Kowalski, P. S., and Anderson, D. G. (2017). Advances in the delivery of RNA therapeutics: from concept to clinical reality. Genome Med. 9:60. doi: 10.1186/s13073-017-0450-0
Kapadia, S. B., Brideau-Andersen, A., and Chisari, F. V. (2003). Interference of hepatitis C virus RNA replication by short interfering RNAs. Proc. Natl. Acad. Sci. U.S.A. 100, 2014-2018. doi: 10.1073/pnas.252783999

Kim, D. H., Longo, M., Han, Y., Lundberg, P., Cantin, E., and Rossi, J. J. (2004). Interferon induction by siRNAs and ssRNAs synthesized by phage polymerase. Nat. Biotechnol. 22, 321-325. doi: 10.1038/nbt940

Kok, K. H., Lui, P. Y., Ng, M. H., Siu, K. L., Au, S. W., and Jin, D. Y. (2011). The double-stranded RNA-binding protein PACT functions as a cellular activator of RIG-I to facilitate innate antiviral response. Cell Host Microbe 9, 299-309. doi: 10.1016/j.chom.2011.03.007

Kraft, C. S., Hewlett, A. L., Koepsell, S., Winkler, A. M., Kratochvil, C. J., Larson, L., et al. (2015). The use of TKM-100802 and convalescent plasma in 2 patients with ebola virus disease in the United States. Clin. Infect. Dis. 61, 496-502. doi: $10.1093 / \mathrm{cid} / \mathrm{civ} 334$

Kumar, P., Ban, H. S., Kim, S. S., Wu, H., Pearson, T., Greiner, D. L., et al. (2008). T cell-specific siRNA delivery suppresses HIV-1 infection in humanized mice. Cell 134, 577-586. doi: 10.1016/j.cell.2008.06.034

Macrae, I. J., Zhou, K., Li, F., Repic, A., Brooks, A. N., Cande, W. Z., et al. (2006). Structural basis for double-stranded RNA processing by Dicer. Science 311, 195-198. doi: 10.1126/science.1121638

Maillard, P. V., Van der Veen, A. G., Deddouche-Grass, S., Rogers, N. C., Merits, A., and Reis, E. S. C. (2016). Inactivation of the type I interferon pathway reveals long double-stranded RNA-mediated RNA interference in mammalian cells. EMBO J. 35, 2505-2518. doi: 10.15252/embj.201695086

Makeyev, E. V., and Bamford, D. H. (2000). Replicase activity of purified recombinant protein $\mathrm{P} 2$ of double-stranded RNA bacteriophage phi6. EMBO J. 19, 124-133. doi: 10.1093/emboj/19.1.124

Minks, M. A., West, D. K., Benvin, S., and Baglioni, C. (1979). Structural requirements of double-stranded RNA for the activation of 2,5'-oligo(A) polymerase and protein kinase of interferon-treated HeLa cells. J. Biol. Chem. $254,10180-10183$.

Morrissey, D. V., Lockridge, J. A., Shaw, L., Blanchard, K., Jensen, K., Breen, W., et al. (2005). Potent and persistent in vivo anti-HBV activity of chemically modified siRNAs. Nat. Biotechnol. 23, 1002-1007. doi: 10.1038/nbt1122

Musacchio, T., and Torchilin, V. P. (2013). siRNA delivery: from basics to therapeutic applications. Front. Biosci. 18:58. doi: 10.2741/4087

Nair, J. K., Willoughby, J. L., Chan, A., Charisse, K., Alam, M. R., Wang, Q., et al. (2014). Multivalent $\mathrm{N}$-acetylgalactosamine-conjugated siRNA localizes in hepatocytes and elicits robust RNAi-mediated gene silencing. J. Am. Chem. Soc. 136, 16958-16961. doi: 10.1021/ja505986a

Naso, M. F., Tomkowicz, B., Perry, W. L., and Strohl, W. R. (2017). Adenoassociated virus (AAV) as a vector for gene therapy. BioDrugs 31, 317-334. doi: 10.1007/s40259-017-0234-5

Niehl, A., Soininen, M., Poranen, M. M., and Heinlein, M. (2018). Synthetic biology approach for plant protection using dsRNA. Plant Biotechnol. J. 16, 1679-1687. doi: 10.1111/pbi.12904

Nygårdas, M., Vuorinen, T., Aalto, A. P., Bamford, D. H., and Hukkanen, V. (2009). Inhibition of coxsackievirus B3 and related enteroviruses by antiviral short interfering RNA pools produced using phi6 RNA-dependent RNA polymerase. J. Gen. Virol. 90(Pt 10), 2468-2473. doi: 10.1099/vir.0.011338-0

Olejniczak, M., Polak, K., Galka-Marciniak, P., and Krzyzosiak, W. J. (2011). Recent advances in understanding of the immunological off-target effects of siRNA. Curr. Gene Ther. 11, 532-543. doi: 10.2174/156652311798192770

Paavilainen, H., Lehtinen, J., Romanovskaya, A., Nygårdas, M., Bamford, D. H., Poranen, M. M., et al. (2016). Inhibition of clinical pathogenic herpes simplex virus 1 strains with enzymatically created siRNA pools. J. Med. Virol. 88, 2196-2205. doi: 10.1002/jmv.24578

Paavilainen, H., Lehtinen, J., Romanovskaya, A., Nygårdas, M., Bamford, D. H., Poranen, M. M., et al. (2017). Topical treatment of herpes simplex virus infection with enzymatically created siRNA swarm. Antivir. Ther. 22, 631-637. doi: $10.3851 / \mathrm{imp} 3153$

Palliser, D., Chowdhury, D., Wang, Q. Y., Lee, S. J., Bronson, R. T., Knipe, D. M., et al. (2006). An siRNA-based microbicide protects mice from lethal herpes simplex virus 2 infection. Nature 439, 89-94. doi: 10.1038/nature04263

Pozzi, D., Marchini, C., Cardarelli, F., Salomone, F., Coppola, S., Montani, M., et al (2014). Mechanistic evaluation of the transfection barriers involved in lipidmediated gene delivery: interplay between nanostructure and composition. Biochim. Biophys. Acta 1838, 957-967. doi: 10.1016/j.bbamem.2013.11.014 
Qiu, Y., Xu, Y., Zhang, Y., Zhou, H., Deng, Y. Q., Li, X. F., et al. (2017). Human virus-derived small RNAs can confer antiviral immunity in mammals. Immunity 46, 992-1004.e1005. doi: 10.1016/j.immuni.2017.05.006

Randall, G., Grakoui, A., and Rice, C. M. (2003). Clearance of replicating hepatitis $\mathrm{C}$ virus replicon RNAs in cell culture by small interfering RNAs. Proc. Natl. Acad. Sci. U.S.A. 100, 235-240. doi: 10.1073/pnas.02355 24100

Reynolds, A., Leake, D., Boese, Q., Scaringe, S., Marshall, W. S., and Khvorova, A. (2004). Rational siRNA design for RNA interference. Nat. Biotechnol. 22, 326-330. doi: 10.1038/nbt936

Rohayem, J., Jäger, K., Robel, I., Scheffler, U., Temme, A., and Rudolph, W. (2006). Characterization of norovirus 3Dpol RNA-dependent RNA polymerase activity and initiation of RNA synthesis. J. Gen. Virol. 87(Pt 9), 2621-2630. doi: 10.1099/vir.0.81802-0

Romanovskaya, A., Paavilainen, H., Nygårdas, M., Bamford, D. H., Hukkanen, V., and Poranen, M. M. (2012). Enzymatically produced pools of canonical and Dicer-substrate siRNA molecules display comparable gene silencing and antiviral activities against herpes simplex virus. PLoS ONE 7:e51019. doi: 10.1371/journal.pone.0051019

Romanovskaya, A., Sarin, L. P., Bamford, D. H., and Poranen, M. M. (2013). Highthroughput purification of double-stranded RNA molecules using convective interaction media monolithic anion exchange columns. J. Chromatogr. A 1278, 54-60. doi: 10.1016/j.chroma.2012.12.050

Rozema, D. B., Lewis, D. L., Wakefield, D. H., Wong, S. C., Klein, J. J., Roesch, P. L., et al. (2007). Dynamic PolyConjugates for targeted in vivo delivery of siRNA to hepatocytes. Proc. Natl. Acad. Sci. U.S.A. 104, 12982-12987. doi: 10.1073/pnas.0703778104

Scarborough, R. J., and Gatignol, A. (2017). RNA interference therapies for an HIV-1 functional cure. Viruses 10:E8. doi: 10.3390/v10010008

Schluep, T., Lickliter, J., Hamilton, J., Lewis, D. L., Lai, C. L., Lau, J. Y., et al. (2017). Safety, tolerability, and pharmacokinetics of ARC-520 injection, an RNA interference-based therapeutic for the treatment of chronic Hepatitis B virus infection, in healthy volunteers. Clin. Pharmacol. Drug Dev. 6, 350-362. doi: $10.1002 /$ cpdd. 318

Schroeder, A., Levins, C. G., Cortez, C., Langer, R., and Anderson, D. G. (2010). Lipid-based nanotherapeutics for siRNA delivery. J. Intern. Med. 267, 9-21. doi: 10.1111/j.1365-2796.2009.02189.x

Seo, G. J., Kincaid, R. P., Phanaksri, T., Burke, J. M., Pare, J. M., Cox, J. E., et al. (2013). Reciprocal inhibition between intracellular antiviral signaling and the RNAi machinery in mammalian cells. Cell Host Microbe 14, 435-445. doi: 10.1016/j.chom.2013.09.002

Shabalina, S. A., and Koonin, E. V. (2008). Origins and evolution of eukaryotic RNA interference. Trends Ecol. Evol. 23, 578-587. doi: 10.1016/j.tree.2008.06.005

Sioud, M. (2009). Deciphering the code of innate immunity recognition of siRNAs. Methods Mol. Biol. 487, 41-59. doi: 10.1007/978-1-60327-547-7_2

Sohail, M., Doran, G., Riedemann, J., Macaulay, V., and Southern, E. M. (2003). A simple and cost-effective method for producing small interfering RNAs with high efficacy. Nucleic Acids Res. 31:e38. doi: 10.1093/nar/gng038

Streinu-Cercel, A., Gane, E., Cheng, W., Sievert, W., Roberts, S., Ahn, S. H., et al. (2017). A phase $2 \mathrm{a}$ study evaluating the multi-dose activity of ARB-1467 in HBeAg positive and negative virally suppressed subjects with hepatitis B. J. Hepatol. 66, S688-S689. doi: 10.1016/S0168-8278(17) 31850-0
Su, T. H., and Liu, C. J. (2017). Combination therapy for chronic hepatitis B: current updates and perspectives. Gut Liver 11, 590-603. doi: 10.5009/gnl16215

Sun, G., and Riggs, A. D. (2017). A simple and cost-effective approach for in vitro production of sliced siRNAs as potent triggers for RNAi. Mol. Ther. Nucleic Acids 8, 345-355. doi: 10.1016/j.omtn.2017.07.008

Symonds, G., Bartlett, J. S., Kiem, H. P., Tsie, M., and Breton, L. (2016). Cell-delivered entry inhibitors for HIV-1: ccr5 downregulation and blocking virus/membrane Fusion in defending the host cell population. AIDS Patient Care STDS 30, 545-550. doi: 10.1089/apc.2016.0245

Tafer, H. (2014). Bioinformatics of siRNA design. Methods Mol. Biol. 1097, 477-490. doi: 10.1007/978-1-62703-709-9_22

Tenllado, F., Martínez-García, B., Vargas, M., and Díaz-Ruíz, J. R. (2003). Crude extracts of bacterially expressed dsRNA can be used to protect plants against virus infections. BMC Biotechnol. 3:3. doi: 10.1186/1472-6750-3-3

tenOever, B. R. (2017). Questioning antiviral RNAi in mammals. Nat. Microbiol. 2:17052. doi: 10.1038/nmicrobiol.2017.52

Villegas, P. M., Ortega, E., Villa-Tanaca, L., Barron, B. L., and Torres-Flores, J. (2018). Inhibition of dengue virus infection by small interfering RNAs that target highly conserved sequences in the NS4B or NS5 coding regions. Arch. Virol. 163, 1331-1335. doi: 10.1007/s00705-018-3757-2

Wooddell, C., Zhu, R., Hamilton, H., Chu, Q., Sternard, H., Schumacher, J., et al. (2018). Development of subcutaneously administered RNAi therapeutic ARO-HBV for chronic hepatitis B virus infection. J. Hepatol. 68, S18-S19. doi: 10.1016/S0168-8278(18)30255-1

Wooddell, C. I., Rozema, D. B., Hossbach, M., John, M., Hamilton, H. L., Chu, Q., et al. (2013). Hepatocyte-targeted RNAi therapeutics for the treatment of chronic hepatitis B virus infection. Mol. Ther. 21, 973-985. doi: 10.1038/mt.2013.31

Wooddell, C. I., Yuen, M. F., Chan, H. L., Gish, R. G., Locarnini, S. A., Chavez, D., et al. (2017). RNAi-based treatment of chronically infected patients and chimpanzees reveals that integrated hepatitis B virus DNA is a source of HBsAg. Sci. Transl. Med. 9:eaan0241. doi: 10.1126/scitranslmed.aan0241

Yang, D., Buchholz, F., Huang, Z., Goga, A., Chen, C. Y., Brodsky, F. M., et al. (2002). Short RNA duplexes produced by hydrolysis with Escherichia coli RNase III mediate effective RNA interference in mammalian cells. Proc. Natl. Acad. Sci. U.S.A. 99, 9942-9947. doi: 10.1073/pnas.152327299

Zamora, M. R., Budev, M., Rolfe, M., Gottlieb, J., Humar, A., Devincenzo, J., et al. (2011). RNA interference therapy in lung transplant patients infected with respiratory syncytial virus. Am. J. Respir. Crit. Care Med. 183, 531-538. doi: 10.1164/rccm.201003-0422OC

Zhu, B., Hernandez, A., Tan, M., Wollenhaupt, J., Tabor, S., and Richardson, C. C. (2015). Synthesis of 2'-Fluoro RNA by Syn5 RNA polymerase. Nucleic Acids Res. 43:e94. doi: 10.1093/nar/gkv367

Conflict of Interest Statement: The authors declare that the research was conducted in the absence of any commercial or financial relationships that could be construed as a potential conflict of interest.

Copyright (c) 2018 Levanova and Poranen. This is an open-access article distributed under the terms of the Creative Commons Attribution License (CC BY). The use, distribution or reproduction in other forums is permitted, provided the original author(s) and the copyright owner(s) are credited and that the original publication in this journal is cited, in accordance with accepted academic practice. No use, distribution or reproduction is permitted which does not comply with these terms. 